\title{
Incidence and Prevalence of Hard Ticks in Ruminants of Al-Ahsa Oasis Region, Kingdom of Saudi Arabia
}

\author{
Mohammad H. Abdally ${ }^{1}$, Theeb M. Al-Marri ${ }^{2}$, Hussain M. Abdally ${ }^{1}$ and Omar A. Al-Jabr ${ }^{1 *}$ \\ ${ }^{I}$ Department of Microbiology, College of Veterinary Medicine, King Faisal University, P.O. Box: 400, Al-Ahsa, 31982, Saudi Arabia \\ ${ }^{2}$ Veterinary Diagnostic Laboratory, Ministry of Environment, Water and Agriculture, King Fahad Road, Al-Ahsa, 36341, Saudi Arabia \\ *Corresponding author's Email: oal_jabr@hotmail.com; (DORCiD: 0000-0001-9342-343X
}

\begin{abstract}
In the present study, a number of camels, cattle, sheep, and goat herds have been examined and followed up to record the incidence of tick infestation in Al-Ahsa Oasis in the Eastern Region of the Kingdom of Saudi Arabia. From 24 herds distributed in eleven localities, a total of 4068 animals (123 camels, 60 cattle, 1780 sheep, and 2105 goats) were individually examined every second week during the period from January to December 2010. In total, 5320 ticks were collected from 1125 infested animals (27.65\%). The overall prevalence rate of identified Ixodide ticks was: Hyalomma anatolicum excavatum (18.33\%), Hyalomma dromedarii (17.63\%), Hyalomma anatolicum anatolicum (14.29\%), Rhipicephalus turanicus (14.04\%), Hyalomma impeltatum (11.28\%), Rhipicephalus praetextatus (8.56\%), Hyalomma marginatum turanicum (6.20\%), Haemaphysalis sulcata (3.57\%), Rhipicephalus kohlsi (2.33\%), Hyalomma marginatum rufipes (2.09\%), Hyalomma schulzei (1.03\%), Amblyomma variegatum $(0.47 \%)$, and Amblyomma gemma $(0.18 \%)$. Tick infestation in terms of mean intensity, abundance, and prevalence rates was highest in camels (41 tick/infested camel, 30 ticks/camel, and $73.17 \%$, respectively). This was followed by cattle (15 tick/infested cow, 5 ticks/cow, and 33.33\%, respectively), goats (1.35 tick/infested goat, 0.33 tick/goat, and $23.52 \%$, respectively), and sheep (1.27 tick/infested sheep, 0.3 tick/sheep, and $29.21 \%$, respectively). The incidence rate of ticks significantly increased during the warmest summer months of the year (highest recorded temperature ranged between $47^{\circ} \mathrm{C}$ and $50^{\circ} \mathrm{C}$ ), mainly due to the management practices of farmers. During this period animals were housed and water was supplied ad libitum during hot months, thereby increasing animal density and humidity in the shaded farms. According to the obtained results of the current study, tick control can be started in Al-Ahsa area in early May for all animals with the focus on camels as they are the harbor of the tick biomass, or on goats as they had initially increased in incidence rates.
\end{abstract}

Keywords: Kingdom of Saudi Arabia, Prevalence, Ruminants, Ticks

\section{INTRODUCTION}

Hard ticks of the family Ixodidae include more than 700 species (Guglielmone et al., 2014), most of which are considered highly specialized and obligate blood-sucking vectors that transmit pathogens to human and animals (Jongejan and Uilenberg, 2004; Karim et al., 2017). Among such pathogens are protozoan species of veterinary importance, for example Theileria spp., Babesia spp. and Anaplasma spp., which affect red and white blood cells, leading to severe damages to the infected hosts (Friedhoff, 1997; Alessandra and Santo, 2012). Furthermore, viral tick-borne infections can be zoonotic with grave consequences, and worst of all is the emerging Crimean-Congo Hemorrhagic Fever (CCHF) (Tonbak et al., 2006). CCHF virus can be transmitted via hard ticks of Hyalomma (Dohm et al., 2004) and Rhipicephalus species from animals to humans (Aktas et al., 2012; Bartikova et al., 2017). Both of these ticks were reported from Saudi Arabia (El-Azazy et al., 1997; El-Azazy et al., 2001; Al-Khalifa et al., 2007).

Al-Ahsa oasis is located in the Eastern region of the Kingdom of Saudi Arabia. It has been inhabited by humans for more than 7000 years, mainly as an agricultural heaven in the middle of the desert. It has the world largest palm gardens along with a plethora of agricultural corps and domesticated animals. Camels are dominant in this area, but local breeds of cattle, sheep and goats are also indigenous. In this region, the culture of farming in many places has somewhere lost momentum of developing and adhering to the modern methods of production and health control (Abdallah and Faye, 2013). This situation has created a rare model to study the tick fauna of domesticated animals in this area, and thereby presenting a snapshot of the situation that has been there in many areas in the world but then one century ago.

The present study aimed to explore the hard tick species richness in this oasis and the dynamics of the incidence of ticks in animals. Most of the domesticated animals in the study area did not receive proper acaricide treatment, and planning tick control strategies here aims to reduce risk of outbreak of tick-borne infections. Such outbreak, if occurs, 
might have deep health consequences in a dynamic city that houses hundreds of animal farms within a total population of around one million (https://www.alhasa.gov.sa/SitePages/Home.aspx). Previously, limited survey has reported the presence of some tick species in a small animal sample (Hoogstraal et al., 1981). Therefore, the present study will follow up a number of camels, cattle, sheep and goat herds for a whole year to record the tick species and to establish background information on dynamics of tick infestations for later designing of mitigation plans.

\section{MATERIALS AND METHODS}

\section{Ethical approval}

This research has been conducted according to the national guidelines for research ethics on living organisms (Kingdom of Saudi Arabia, Act No. 321).

\section{Areas of study}

Al-Ahsa Oasis is about $160 \mathrm{Km}$ south of Dammam, the capital of the Eastern Region of Saudi Arabia (Figure 1). Geographically, the sampled areas are located between $49^{\circ} 10^{\prime} \mathrm{E}$ to $49^{\circ} 50^{\prime} \mathrm{E}$ and $25^{\circ} 25^{\prime} \mathrm{N}$ to $25^{\circ} 40^{\prime} \mathrm{N}$, and about 130 $160 \mathrm{~m}$ above sea level. The weather in Al-Ahsa oasis is typical oasis, in which two major lakes are located within an arid desert area, and many springs and wells are found in scattered agricultural farms. Meteorological data on relative humidity and temperature in Al-Ahsa oasis are provided by the Saudi General Authority of Meteorology and Environmental Protection (www.pme.gov.sa; temperature data are summarized in figure 2). Rainfall in that area is scares. In fact, in the year 2010 it rained for a whole week in February, otherwise intermittent showers of rain were experienced a few days during September and November.

\section{Sampled herds}

Location of the farms and number of animals sampled are summarized in table 1 and figure 1. Within Al-Ahsa oasis, 24 herds in farms were included in this study according to the availability of the animals and willingness to cooperate with the researchers. Farming in this area undergoes two different practices depending on the season. The first method was permanent housing, in which animals were kept indoors and fed ad libitum during hot months of the year (from early May to end of September). In the second method of farming practice in this area, herds were "seminomad" and were grazing is practiced in the open fields around the owners' tents or at a maximum distance of $10 \mathrm{~km}$ away to portable houses during moderate and cold months of the year (from October to April). Camel, sheep and goat herds undergo these two practices yearly, but cattle herds are always kept indoors throughout the year. Herd size in sheep farms had a range of 60 to 500 animals per farm, all of which were Naimi breed. Goat farms had a range of 30 to 600 animals per farm of Shami or Aardhiat breeds. Cattle farms had 3 to 25 animals of a local breed. Camel farms had 30 to 80 animals that all were Arabian breed. Derived by the market demands, animals in sheep and goat farms were constantly replaced with new individuals, unlike animals in camel and cattle farms. Accordingly, an incidence and prevalence rate presented in this study represents farm-level indices.

\section{Sampling methodology}

Farms were regularly visited every second week during the period starting from January 2010 until the end of December 2010. Approximately $10 \%$ of all animals in any farm were subject to examination. Upon animal examination, all present ticks were removed from the animals using tweezers and rubber gloves by following instructions of Hoogstraal et al. (1981) and Abdally (2008). The locations of the collected ticks were marked, and they were stored in $70 \%$ ethyl alcohol. In some cases where alcohol was not available fresh tick samples were kept in plain containers and transported to the examination lab, where they were kept in a freezer $\left(-20^{\circ} \mathrm{C}\right)$ for a short period (up to 30 minutes) to stabilize the tick before morphological examination. From each examined animal the ticks were removed and counted. Tick identification was done according to the keys of Hoogstraal et al. (1981) and Walker et al. (2003). Due to logistic constrains, only adult female ticks were diagnosed to the species level and included in this study. As well, it was not possible to collect information on age and sex of the examined animals in all occasions, therefore such data was not included in the statistical analysis.

\section{Statistical analysis}

Collected data were transformed to templates in Microsoft Excel software to produce summary and descriptive statistics. The incidence rate of tick infestation was employed here as the percentage of infested animals at a given time interval within the year. The overall prevalence rate of tick infestation was employed here as the percentage of animals infested with ticks during the whole period of the study. The mean intensity rate employed here was calculated as the total number of collected ticks divided by the number of infested animals, while the mean abundance rate was calculated as the total number of collected ticks divided by the total number of examined animals. Seasons 
were defined as winter: December-February, spring: March-May, summer: June-August, and autumn: SeptemberNovember. To explore the seasonal differences in the incidence of ticks, Chi-suqare test was employed, where observed integers were the cumulative number of found ticks of all species in all animal types, and the expected percentages were set as $25 \%$ for each season. Depending on sample size, Fisher's exact text or Student's T-test were employed to explore differences within the study populations. Using any statistics, the results were considered significant at $p$ values $<0.05$.

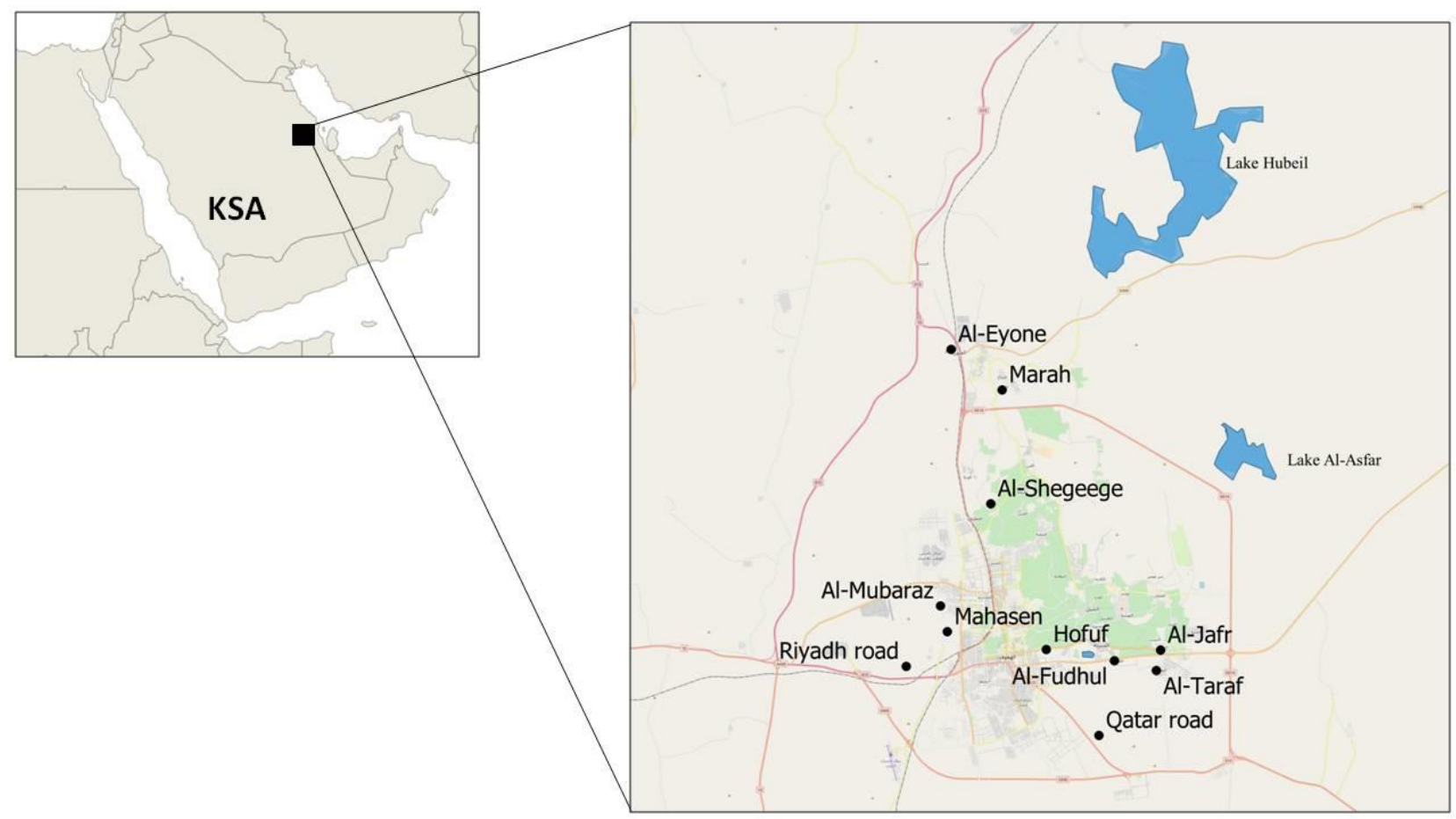

Figure 1. Map of the Kingdom of Saudi Arabia (KSA), showing the 11 areas in Al-Ahsa oasis (black circle) where animal sampling took place from January to December 2010.

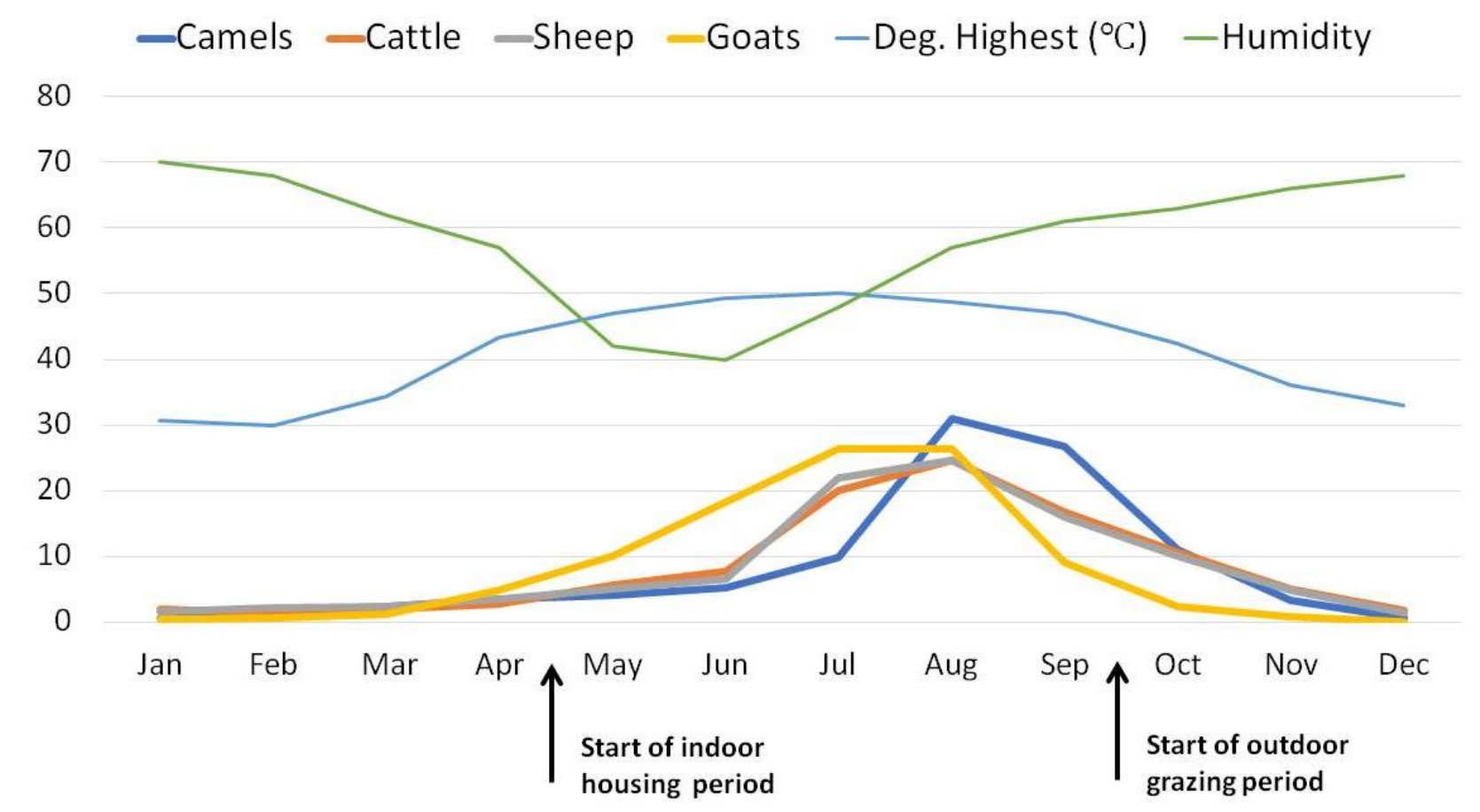

Figure 2. Seasonal variations in incidence of recovered hard ticks from camels, cattle, sheep and goats examined in 2010 in Al-Ahsa oasis, Kingdom of Saudi Arabia. 
Table 1. Number of animals examined and incidence rates of hard ticks found in domesticated ruminant herds in 11 localities in Al-Ahsa oasis, Kingdom of Saudi Arabia, during the period from January 2010 to December 2010

\begin{tabular}{|c|c|c|c|c|c|c|c|c|c|}
\hline \multirow{2}{*}{ Locality } & \multicolumn{2}{|c|}{ Camel } & \multicolumn{2}{|c|}{ Sheep } & \multicolumn{2}{|c|}{ Goats } & \multicolumn{2}{|c|}{ Cattle } & \multirow{2}{*}{ Total } \\
\hline & Examined & Infested (\%) & Examined & Infested (\%) & Examined & Infested (\%) & Examined & Infested (\%) & \\
\hline Al-Hufof & 5 & $5(100 \%)$ & 80 & $20(25 \%)$ & 40 & $13(30.23 \%)$ & 6 & $1(16.67 \%)$ & 134 \\
\hline Al-Mubaraz & 5 & $5(100 \%)$ & 80 & $30(37.5 \%)$ & 40 & $20(50 \%)$ & 4 & $1(25 \%)$ & 129 \\
\hline Mahasen & - & - & 70 & $30(42.86 \%)$ & 95 & $35(36.84 \%)$ & - & - & 165 \\
\hline Ryiadh Rd * & 32 & $22(68.75 \%)$ & 490 & $120(24.49 \%)$ & 320 & $120(37.5 \%)$ & - & - & 842 \\
\hline Qatar Rd.* & 22 & $10(45.45 \%)$ & 430 & $130(30.23 \%)$ & 530 & $130(24.53 \%)$ & 25 & $8(32 \%)$ & 1007 \\
\hline Al-Oyone & 13 & $8(61.54 \%)$ & 90 & $40(44.44 \%)$ & 180 & $30(16.67 \%)$ & 5 & $3(60 \%)$ & 288 \\
\hline AL-Marah & 13 & $10(76.92 \%)$ & 75 & $25(33.33 \%)$ & 225 & $25(11.11 \%)$ & 4 & $2(50 \%)$ & 317 \\
\hline Al-Shegeege & 7 & $7(100 \%)$ & 58 & $18(31.03 \%)$ & 150 & $30(20 \%)$ & 4 & $1(25 \%)$ & 219 \\
\hline Al-Fudhule & 3 & $3(100 \%)$ & 93 & $23(24.73 \%)$ & 100 & $20(20 \%)$ & 5 & $2(40 \%)$ & 201 \\
\hline Al-Jafr & 18 & $15(83.33 \%)$ & 104 & $24(23.08 \%)$ & 131 & $31(23.66 \%)$ & 4 & $1(25 \%)$ & 257 \\
\hline Al-Taraf & 5 & $5(100 \%)$ & 210 & $60(28.57 \%)$ & 291 & $41(14.09 \%)$ & 3 & $1(33.33 \%)$ & 509 \\
\hline Total & 123 & $90(73.17 \%)$ & 1780 & $520(29.21 \%)$ & 2105 & $495(23.52 \%)$ & 60 & $20(33.33 \%)$ & 4068 \\
\hline
\end{tabular}

Rd.*: road; herd farms located in vicinity of the main road.

\section{RESULTS}

A total of 4068 animals were examined (Table 1), among which 1125 animals were infested with hard ticks, giving an overall prevalence rate of $27.65 \%$. The highest prevalence of ticks was found in camels $\left(\chi^{2}=65.5031\right.$, the p-value is $<$ $0.0 \mathrm{p} 1)$, in which 90 of the examined 123 camels $(73.17 \%)$ were found infested with at least one tick during this oneyear cohort study. Camels had also the highest mean intensity rate of tick infestations; a total of 3690 ticks were recovered from 90 camels (69.36\% of all collected ticks in this study), giving a mean intensity of 41 tick/infested camel, and mean abundance rate of 30 ticks/camel. Cattle were second in mean intensity and abundance rates; 15 tick/infested cow and 5 ticks/ cow, respectively, and had an overall prevalence rate of 33.33\%. In goats the mean intensity rate was 1.35 tick/infested goat, and the mean abundance rate was 0.33 tick /goat, while the overall prevalence rate was $23.52 \%$. Similarly, sheep had intensity and abundance rates of 1.27 tick/infested sheep and 0.3 tick/sheep, respectively. However, the overall prevalence rate of ticks in sheep was $29.21 \%$.

In this study, a total of 5320 ticks were collected (Table 2), among which 13 species belonging to four genera were identified as follows in a descending order of prevalence rates: Hyalomma anatolicum excavatum (18.33\%), Hyalomma dromedarii (17.63\%), Hyalomma anatolicum anatolicum (14.29\%), Rhipicephalus turanicus (14.04\%), Hyalomma impeltatum (11.28\%), Rhipicephalus praetextatus (8.56\%), Hyalomma marginatum turanicum (6.20\%), Haemaphysalis sulcata (3.57\%), Rhipicephalus kohlsi (2.33\%), Hyalomma margin rufipes (2.09\%), Hyalomma schulzei (1.03\%), Amblyomma variegatum (0.47\%), and Amblyomma gemma (0.18\%). Ticks of the genus Hyalomma were generally the most diverse and commonly found in all species of examined animals, followed by Rhipicephalus then Haemaphysalis, while ticks of the genus Amblyomma were the least found and were restricted to cattle.

Ticks that had the highest incidence rates were mostly collected from camels, albeit being found in other types of examined animals (Table 2). The least incident tick species were those found in one or two animal species. One tick species was found only in camels (Hy. schulzei), two tick species were only found in cattle (A. variegatum and A. gemma) and two tick species were only found in sheep and goats (R. kohlsi and Haem. sulcata).

The four types of examined domesticated animals had similar tick species richness; goats were found infested with eight tick species, camels, sheep, and cattle were infested with nine tick species (Table 2 and figure 3 ). Nonetheless, during the study period, at least one animal per farm was found infested with a hard tick regardless of the animal type, herd type and herd size; hence none of the included farms were tick-free. Furthermore, all animal herds were found infested with at least one tick species. All camels in herds that had three to seven animals $(\mathrm{N}=5)$ had prevalence rates of $100 \%$. In larger size camel herds, the prevalence rates ranged from $45.45 \%$ to $83.33 \%$. Prevalence of ticks in cattle herd ranged from $16.76 \%$ to $60 \%$. All cattle farms except one had less than six animals in the herd. Prevalence level of ticks in sheep herd ranged from $24.49 \%$ to $44.44 \%$. Prevalence level of ticks in goat herd ranged from $11.11 \%$ to $50 \%$.

Ticks were most abundant in the warmest summer months of the year (Table $3 ; \chi^{2}=2288.289$, the $p$-value is < 0.01), where ticks of all species were found in June, July, and August with an overall incidence rates of $10.83 \%$, $16.20 \%$, and $24.59 \%$, respectively. In these months, the highest recorded degrees ranged from $47^{\circ} \mathrm{C}$ to $50^{\circ} \mathrm{C}$, while the lowest temperatures ranged from $22.9^{\circ} \mathrm{C}$ to $26.6^{\circ} \mathrm{C}$, with no precipitation at all at any time during these months, with 
maximum humidity of $70 \%$ in January and slowly dropping to $40 \%$ in June. On the other hand, the incidence and abundance of ticks dropped during the colder winter season (Table 3 and figure 2), were only seven out of the total 13 tick species were found in January, February and December months, giving an overall abundance rates of $2.07 \%$, $2.88 \%$ and $2.01 \%$, respectively.

Animal species differed in their trend of harboring ticks during the year (Figure 2). The first animals that exhibited increase in incidence rates of hard ticks were goats, which showed gradual increase in incidence rate during May and peaked during August, then dropped sharply until October. The incidence rates of ticks showed almost identical trend in cattle and sheep, in which the rate started to rise sharply in June, peaked from July until August, and then dropped slowly towards December. Camels were the last animals to show increase in the incidence rates, which started to build up sharply in July, peaked in August, and then slowly dropped from September through October.

Tick species that had prevalence rates of more than $3 \%$ were observed throughout the year (Table 4), namely: Hy. a. excavatum, Hy. dromedarii, Hy. a. anatolicum, R. turanicus, Hy.m. turanicum, R. praetextatus and Haem. sulcata. An exception of the previous observation is Hy. impeltatum, which had a prevalence rate of $11.28 \%$, but was not observed in any examined animal in December and January. The rest of the tick species could not be seen in the examined animals for at least two months during that year (R. kohlsi, Hy. impelt, and Hy. m. rufi). Some of the tick species were not found for five months in row (Hy. schulzei), six months (A. variegatum) and up to eight months in row during that year (A. gemma).

In camels, Hy. dromedarii was the most abundant tick species and accounted for $24.39 \%$ of all tick infestations (Figure 3), followed by Hy. a. excavatum (21.68\%). Infestation with Hy. a. anatolicum in cattle accounted for $33.3 \%$ of all tick infestations, followed by $R$. turanicus (15.7\%). However, infestation with $R$. turanicus accounted for $34.92 \%$ of all tick infestations in sheep and $45.71 \%$ of all tick infestations in goats. The second most important tick species infesting sheep was Hy. a. excavatum (22.22\%), while in goats it was Haem. sulcata (17.14\%).

All the observed ticks placed themselves in different parts of host body (Figure 4). None of the examined animals had ticks on places readily exposed to sun light, for example on the backs, on top of the head or on the back of the neck. The majority of the found ticks were collected from the necks $\left(\chi^{2}=41.074\right.$, the $p$-value is <0.01) of camels, goats and cattle $(41 \%, 29 \%$, and $26 \%$, respectively). Astonishingly enough, the neck was the least chosen place on sheep for tick to take its blood from (10\% of all found ticks). Generally, 35.90\% (1910) of all collected ticks were found in the necks, followed by chest (23.12\% of all collected ticks), legs $(19.17 \%)$, on udders $(10.53 \%)$, on ears $(5.83 \%)$, and least were under the tail.
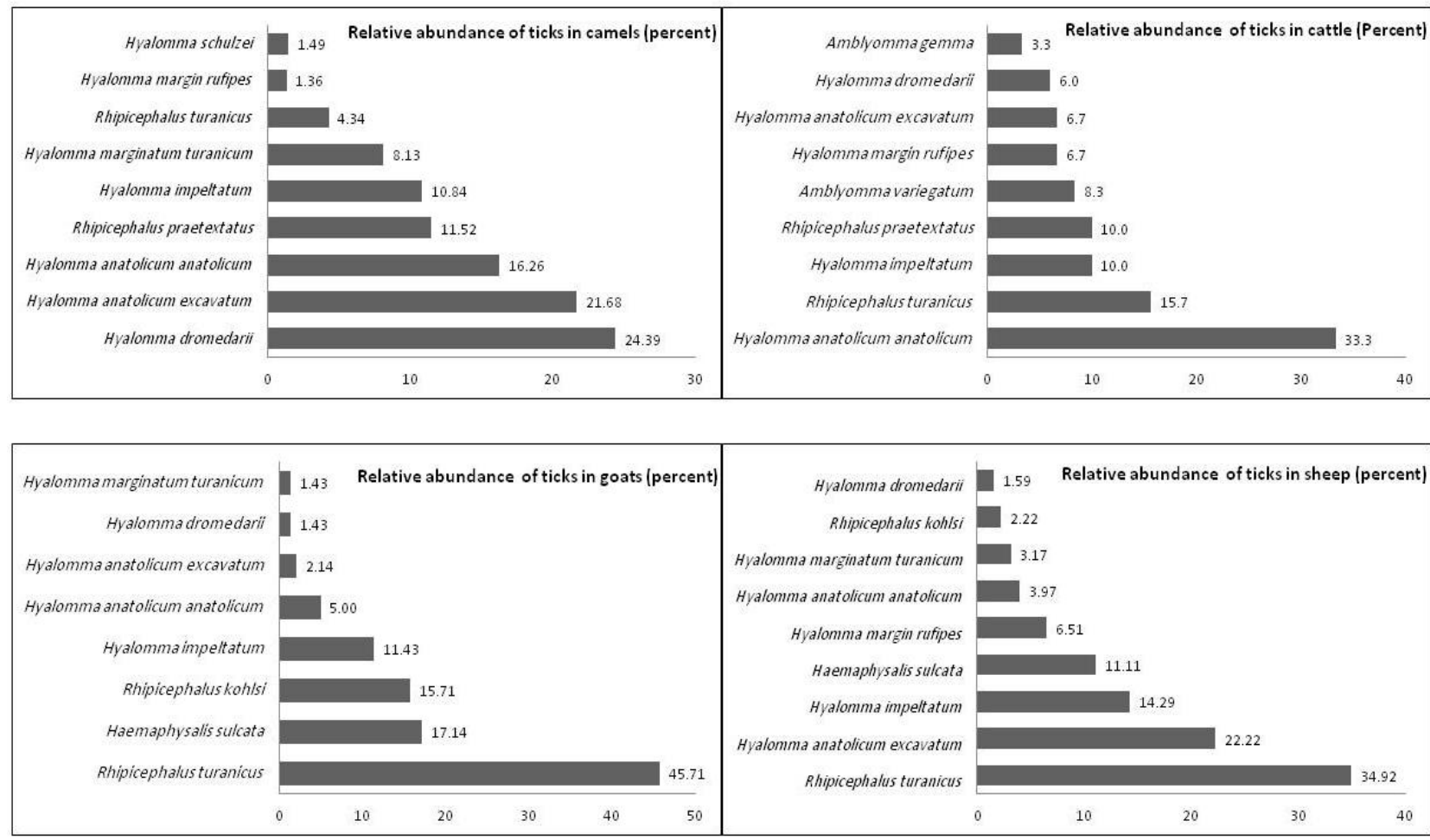

Figure 3. Percentage of tick species found in sampled animals in Al-Ahsa oasis in 2010. 


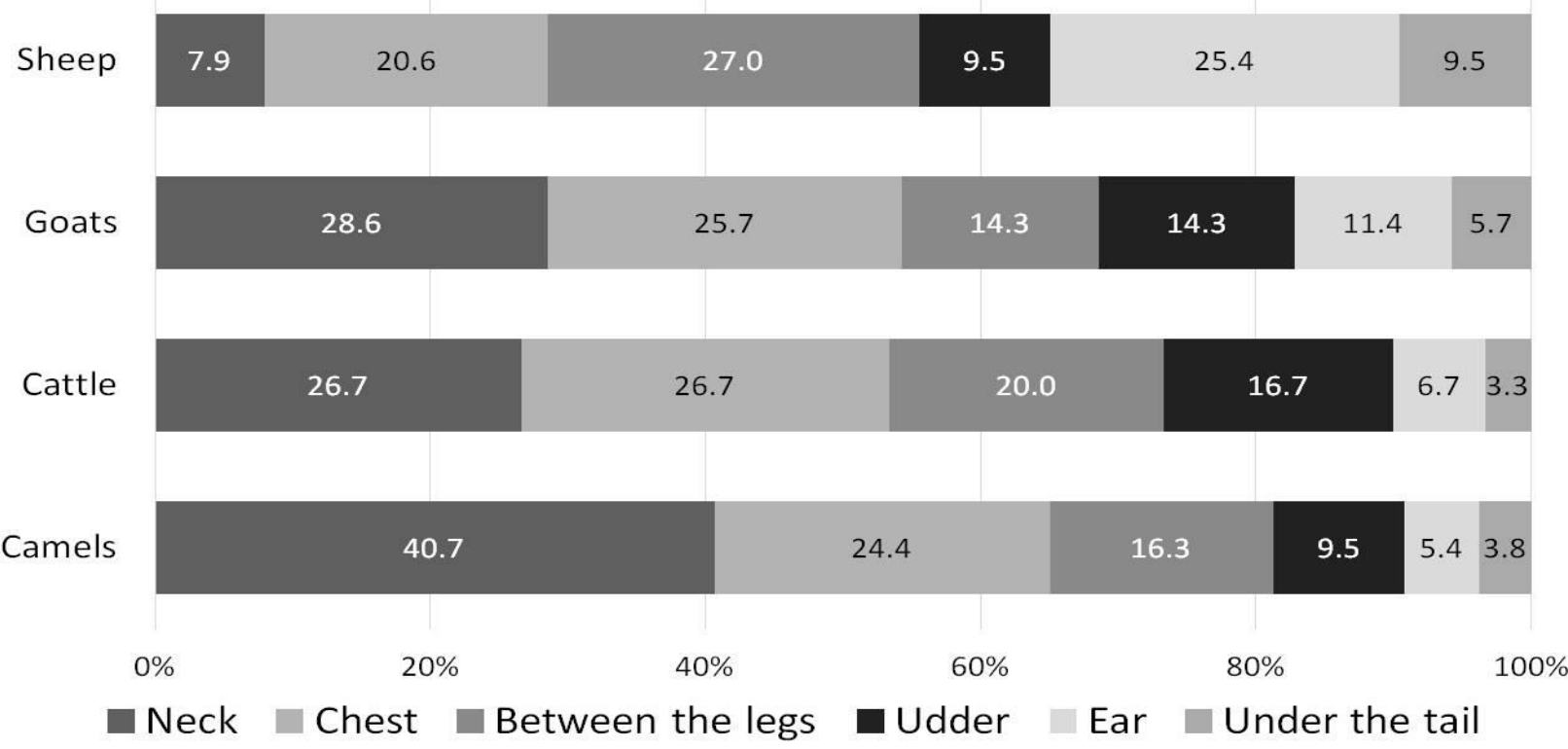

Figure 4. Predilection sites of ticks naturally infesting domesticated ruminants in Al-Ahsa oasis, Kingdom of Saudi Arabia.

Table 2. Numbers and prevalence of recovered hard tick species from domesticated ruminants during January December 2010 in Al-Ahsa Oasis, KSA.

\begin{tabular}{lcccccc}
\hline \multirow{2}{*}{ Tick species } & \multicolumn{2}{c}{ Hosts } & \multirow{2}{*}{ Total } & \multirow{2}{*}{ Prevalence \% } \\
\cline { 2 - 5 } & Camels & Sheep & Goats & Cattle & & 0.47 \\
Amblyomma variegatum & - & - & - & 25 & 25 & 10 \\
Amblyomma gemma & - & - & - & 10 & 0.18 \\
Rhipicephalus kohlsi & - & 14 & 110 & - & 124 & 2.33 \\
Haemaphysalis sulcata & - & 70 & 120 & - & 190 & 3.57 \\
Hyalomma anatolicum anatolicum & 600 & 25 & 35 & 100 & 760 & 14.29 \\
Hyalomma anatolicum excavatum & 800 & 140 & 15 & 20 & 975 & 18.33 \\
Hyalomma dromedarii & 900 & 10 & 10 & 18 & 938 & 17.63 \\
Hyalomma impeltatum & 400 & 90 & 80 & 30 & 600 & 11.28 \\
Hyalomma marginatum turanicum & 300 & 20 & 10 & - & 330 & 6.20 \\
Hyalomma margin rufipes & 50 & 41 & - & 20 & 111 & 2.09 \\
Hyalomma schulzei & 55 & - & - & - & 55 & 1.03 \\
Rhipicephalus praetextatus & 425 & - & - & 30 & 455 & 8.56 \\
Rhipicephalus turanicus & 160 & 220 & 320 & 47 & 747 & 14.04 \\
\hline Total number of collected ticks & 3690 & 630 & 700 & 300 & 5320 & - \\
\hline \% & 69.36 & 11.84 & 13.16 & 5.64 & - & - \\
\hline
\end{tabular}

Table 3. Seasonal variation in incidence of recovered hard tick species from domesticated ruminants during January December 2010 in Al-Ahsa Oasis, KSA.

\begin{tabular}{|c|c|c|c|c|c|c|c|}
\hline \multirow{2}{*}{ Tick species } & \multicolumn{4}{|c|}{ Counts per season } & \multirow{2}{*}{ Total } & \multirow{2}{*}{$\begin{array}{c}\chi^{2} \\
2288.29\end{array}$} & \multirow{2}{*}{$\begin{array}{c}p \text {-value } \\
<0.00001\end{array}$} \\
\hline & Winter & Spring & Summer & Autumn & & & \\
\hline Amblyomma variegatum & - & 3 & 17 & 5 & 25 & & \\
\hline Amblyomma geтma & - & - & 8 & 2 & 10 & & \\
\hline Rhipicephalus kohlsi & 5 & 29 & 59 & 31 & 124 & & \\
\hline Haemaphysalis sulcata & 15 & 41 & 94 & 40 & 190 & & \\
\hline $\begin{array}{l}\text { Hyalomma anatolicum } \\
\text { anatolicum }\end{array}$ & 75 & 196 & 321 & 168 & 760 & & \\
\hline $\begin{array}{l}\text { Hyalomma anatolicum } \\
\text { excavatum }\end{array}$ & 85 & 225 & 464 & 201 & 975 & & \\
\hline Hyalomma dromedarii & 62 & 97 & 590 & 189 & 938 & & \\
\hline Hyalomma impeltatum & 10 & 130 & 350 & 110 & 600 & & \\
\hline $\begin{array}{l}\text { Hyalomma marginatum } \\
\text { turanicum }\end{array}$ & 20 & 46 & 175 & 89 & 330 & & \\
\hline Hyalomma margin rufipes & 1 & 19 & 64 & 27 & 111 & & \\
\hline Hyalomma schulzei & - & 6 & 31 & 18 & 55 & & \\
\hline Rhipicephalus praetextatus & 17 & 121 & 229 & 88 & 455 & & \\
\hline Rhipicephalus turanicus & 80 & 109 & 344 & 214 & 747 & & \\
\hline $\begin{array}{l}\text { Total number of ticks and } \\
\text { incidence rate }\end{array}$ & $370(7 \%)$ & $1022(19.2 \%)$ & $2746(51.6 \%)$ & $1182(22.2 \%)$ & $5320(100 \%)$ & & \\
\hline
\end{tabular}


Table 4. Monthly variation in number of recovered tick species from camels, cattle, sheep and goats during January December 2010 in Al-Ahsa Oasis, KSA

\begin{tabular}{|c|c|c|c|c|c|c|c|c|c|c|c|c|c|}
\hline Tick species & Jan & Feb & Mar & Apr & May & Jun & Jul & Aug & Sep & Oct & Nov & Dec & Total \\
\hline Amblyomma variegatum & 0 & 0 & 0 & 1 & 2 & 3 & 4 & 10 & 5 & 0 & 0 & 0 & 25 \\
\hline Amblyomma gemma & 0 & 0 & 0 & 0 & 0 & 1 & 1 & 6 & 2 & 0 & 0 & 0 & 10 \\
\hline Rhipicephalus kohlsi & 0 & 5 & 6 & 10 & 13 & 15 & 19 & 25 & 18 & 10 & 3 & 0 & 124 \\
\hline Haemaphysalis sulcata & 5 & 8 & 8 & 12 & 21 & 25 & 37 & 32 & 25 & 13 & 2 & 2 & 190 \\
\hline $\begin{array}{l}\text { Hyalomma anatolicum } \\
\text { anatolicum }\end{array}$ & 20 & 35 & 40 & 71 & 85 & 105 & 116 & 100 & 70 & 60 & 38 & 20 & 760 \\
\hline $\begin{array}{l}\text { Hyalomma anatolicum } \\
\text { excavatum }\end{array}$ & 30 & 30 & 50 & 80 & 95 & 104 & 140 & 220 & 101 & 52 & 48 & 25 & 975 \\
\hline Hyalomma dromedarii & 19 & 23 & 26 & 30 & 41 & 100 & 200 & 290 & 100 & 51 & 38 & 20 & 938 \\
\hline Hyalomma impeltatum & 0 & 10 & 20 & 50 & 60 & 70 & 100 & 180 & 40 & 36 & 34 & 0 & 600 \\
\hline $\begin{array}{l}\text { Hyalomma marginatum } \\
\text { turanicum }\end{array}$ & 5 & 5 & 10 & 11 & 25 & 30 & 65 & 80 & 40 & 30 & 19 & 10 & 330 \\
\hline Hyalomma margin rufipes & 0 & 1 & 3 & 6 & 10 & 10 & 15 & 39 & 18 & 5 & 4 & 0 & 111 \\
\hline Hyalomma schulzei & 0 & 0 & 0 & 3 & 3 & 5 & 10 & 16 & 10 & 8 & 0 & 0 & 55 \\
\hline Rhipicephalus praetextatus & 6 & 6 & 18 & 51 & 52 & 64 & 55 & 110 & 53 & 24 & 11 & 5 & 455 \\
\hline Rhipicephalus turanicus & 25 & 30 & 31 & 38 & 40 & 44 & 100 & 200 & 100 & 60 & 54 & 25 & 747 \\
\hline Total number of ticks & 110 & 153 & 212 & 363 & 447 & 576 & 862 & 1308 & 582 & 349 & 251 & 107 & 5320 \\
\hline
\end{tabular}

\section{DISCUSSION}

Observations of the current study clearly demonstrate local adaptation of ticks to survive and nourish albeit the harsh desert environment. High species richness of ticks in the examined animals can ensure constant supply of blood meals, especially from domesticated livestock in the oasis, which have shown to be highly susceptibility to various tick species. Livestock that lived longer in this oasis, such as the local breeds of camels and cattle, were those harbored most of the tick biomass in the studied areas, which suggests probable reduced immunity against tick infestations and/or increased susceptibility to tick infestations (Brossard and Wikel, 2004). Furthermore, the type of camel farming systems sampled in this study were those solely or partially devoted to camel farming. Such farmers in the KSA have traditional way of managing camel health issues (Abdallah and Bernard Faye, 2013). This explains the reason for not treating their animals with anthelmintics, albeit obvious presence of ticks.

The conceived experience among local camel owners is that camels are generally in a better condition and health when they are roaming out in the desert. Although grazing in open fields might have increased the chance of harboring ticks from infested wildlife, grazing animals might on the contrary experience reduced tick abundance due to host-diluting effect (Lydecker et al., 2019). However, population dynamics of ticks can be further complicated by the continuous influx of new animals into the herds, uncontrolled administration of acaricides or anthelmintics, the abundance of susceptible wildlife (Alanazi et al., 2019), and the introduction of ticks by migrating birds (Klitgaard et al., 2019). Indeed, Al-Ahsa oasis is a heaven for thousands of migratory birds, which supports their routs by hosting naturally protected places for bird nesting, good plant cover and plenty of clean surface water (Bird Life International, 2019).

This study reports incidence of $R h$. praetextatus in Saudi Arabia. Here, this tick had a relatively high prevalence rate of $8.56 \%$, mainly found in camels but also in cattle. The origin of this tick could not be traced in this study, but ticks of other species could be introduced to new territories by migrating birds (Klitgaard et al., 2019; Tonelli and Dearborn, 2019) or via imported animals. Rh. praetextatus can transmit Nairobi sheep disease, while in cattle and humans it may cause toxicosis and paralysis (Gothe, 1999; Mans et al., 2004).

Recent reports originated from a nearby governorate showed high prevalence rates of hard tick in camels (85.2\%; Alanazi et al., 2019). However, the later study reported a much higher prevalence rate of ticks in sheep, goats and cattle $(79.1 \%, 74.2 \%$, and $69.2 \%$, respectively) than that in this study. Several factors may have resulted in the observed high incident and abundance of ticks in camels. These factors may include the lack of proper control measures against ticks. Having a semi-nomad farming system may further contribute to the spread of ticks to other farms and being in contact with wildlife reservoirs of ticks (Alanazi et al., 2019). Furthermore, keeping animals in farms for extended periods of time might increase the chances of exposure to ticks, depending on the abundance of ticks in the surrounding environment and in other farm animals as well as in visiting wildlife. In addition, other factors could have contributed to the high abundance of ticks in camel and cattle, which may include the reluctance of using Doramectin in its prescribed dosage to treat camel infested with ecto-parasites due to its potential to induce toxicity in local camels (Abdaly, 2008; Lumaret et al., 2012). Improper and/or uncontrolled usage of acaricides have 
been personally noticed during the present study and might possibly have facilitated building resistance against the locally administered acaricides by indigenous ticks, but that is yet to be tested and proved.

In the present study, it was noticed that adult female ticks of seven species were active throughout the year, while six other species were completely absence from the examined animals for periods extend from two and up to eight months in row during colder months of that year. It is not expected in this study that given the condition of AlAhsa oasis ticks might diapause in winter, as temperatures do not reach low critical points that stimulate this pattern of lifestyle here. Alternatively, the limited sample size of five of the least abundant ticks might also influence its prevalence rates (below $2 \%$ in general), but this is not the case for Hy. impeltatum, which had an overall prevalence rate of $11.28 \%$. The latter tick species is a specialist for livestock living in deserts and hot areas (Walker et al., 2003), but their younger life stages, larval and nymph stages, are usually feeding on birds and/or rodents and probably other domesticated or wild animal species during the colder months of the year (Walker et al., 2003; Alanazi, et al., 2019), which might represent the reservoir for this tick during its absence from domesticated animals.

Locally, the ticks found in this study were previously reported in domesticated livestock in Saudi Arabia (Banaja and Roshdy, 1978; Diab et al., 2006; Abdally, 2008), with Hy. dromedarii being the most prevalent tick in camels followed by $R$. tauranicus in sheep and goats (Alanazi et al., 2019). However, Alanazi et al. (2019) found $R$. tauranicus and Hy. schulzei only in spring season, whereas in the current study $R$. tauranicus was abundant throughout the year, and Hy. schulzei was found in spring but mainly in summer. Disagreement in prevalence rates may be merely attributed to the sample size and the local adaptation of ticks that have tuned its seasonal dynamics to maximize the chances of its survival (Alanazi et al., 2019).

Ticks in other areas of Saudi Arabia (Alanazi et al., 2019) and in similar climatic areas in nearby countries (Robson et al., 1969) have shown similar trend of increased prevalence rates in summer season, both in domesticated animals and wildlife. In tropical areas, adult ticks were more abundant in domesticated animals during the summer season (Walker et al., 2003; Barbieri et al., 2019; Hornok et al., 2020), but conversely in eastern and southern Africa, dramatic increase in mortality rate of ticks was found during the dry season (Randolph, 1994). The summer here in $\mathrm{Al}$-Ahsa is relatively hot and dry, and adult ticks have though no chance to survive in nature under these conditions. Consequently, better chances for tick survival exist if ticks would continually feed on animals that are kept indoors during the dry, hot season. Such housing conditions provide the ticks with suitable moisture and endurable temperature levels, together with higher level of animal aggregation, which is ideal for ticks to persist in the dessert (Robson et al., 1969; Alanazi et al., 2019). On the other hand, larvae and nymph stages were presumably feeding on smaller mammals, such as rodents, canines and/or birds, especially during the relatively colder months of the year (Alanazi et al., 2019).

The current finding suggests that ticks in Al-Ahsa area will first appear in goats starting from May, then in June the tick populations will start to infest cattle and sheep simultaneously, and finally the ticks will build up in numbers in camels. This observed trend coupled with the fact that the sampled animals at Al-Ahsa area got infected with different tick species at different intensity and abundance rates clearly indicates different preference of ticks to certain animal species more than others (Guglielmone et al., 2014). Nonetheless, goats in this area can be considered as a bioforecaster that predicts the beginning of tick infestation in other domesticated animals, and camels as the major contributors of tick biomass to the environment.

The recovered ticks in present study preferably chose the neck, the chest, then between the legs for feeding. An exception to the above trend was found in sheep, where the neck was the least preferable place for ticks to reside, and the chest and between the legs were the predilection site of most of the recovered ticks. Several factors may contribute to the preference of ticks to specific sites on the body of its hosts, including easiness in accessing blood and choosing protected areas (Chandler and Read, 1994), or influence of chemotaxis induced by locally emitted odors (Kariuki et al., 2018).

It is believed that this is the completive and systematic study to explore the seasonal variation of ticks in AlAhsa oasis in Saudi Arabia. Hence, providing important information, that can aid planning control programs against ticks in this region and similar regions. The currently found tick species are known vectors of infections for both man and animals. Al-Ahsa oasis is wealthy in animal resources which can be negatively influenced by diseases that can be transmitted by the abundant ticks in the area. Tick borne pathogens of medical and veterinary importance had been reported in ticks from neighboring areas in Saudi Arabia (Hussein et al., 1991; Harrison et al., 2015).

\section{CONCLUSIONS}

The current results showed that the prevalence rates of ticks started to raise synchronizing the raise in ambient temperatures, but was first evident in goats, then sheep and cattle and lastly in camels. However, the biomass burden of tick infestations has highest in camels, then sheep and goats, and lastly in cattle. The predominant tick species in camels were Hy. dromedarii (24.39\%) and Hy. anatolicum excavatum (21.68\%), in cattle Hy. anatolicum anatolicum 
(33.3\%), and in sheep and goats $R h$. turanicus (34.92\% and $45.71 \%$, respectively). The overall prevalence rates of ticks started to drop in all animals when the temperature started to drop in August until October. This may provide a seasonal bottleneck that should be targeted for control measures. A proposed tick control plan can be initiated in AlAhsa area in early May for all animals or can be focused on camels as the animals that harbored most of the tick biomass in the area, or on goats as those that first experience increases in incidence rates.

\section{DECLARATIONS}

\section{Competing interests}

The authors declare no competing interests.

\section{Acknowledgements}

The authors of this article would like to thank all farmers for accepting participation on this study and making their animals available for sampling. The authors acknowledged Mr. Hussein Al-Isa for his support in tick collection. Special thanks also go to Dr. Mohammad Nafi Solaiman Al-Sabi and Dr. Al-Awad Al-Ombashi for reading and commenting on drafts of this manuscript. Funding of this study was on the expense of the authors and did not receive any funds from any agencies. Nonetheless, the authors acknowledged the support and cooperation of the administration and staff of the Department of Microbiology and the College of Veterinary Medicine at King Faisal University in Al-Ahsa.

\section{Author's contribution}

M. H. Abdally has contributed in conceptualization of the project ideas, funding of the project from his own acquisitions, project administration along the duration of the study, secured resources, contributed in sampling methodology and lab diagnosis, secured the investigation process, facilitating and contributing to the writing of original draft, and overall supervision on the research work. Theeb M. Al-Marri and Hussain M. Abdally have equally secured the availability and using of the resources, secured and used relevant software for data curation, performed formal analysis and validation of the data. Omar A. Al-Jabr has contributed in visualization of the results, discussion, and secured writing, reviewing and editing of the final version of the manuscript.

\section{REFERENCES}

Abdallah HR and Faye B (2013). Typology of camel farming system in Saudi Arabia. Emirates Journal of Food and Agriculture, 25: 250-260. DOI: https://www.doi.org/10.9755/ejfa.v25i4.15491

Abdally MH (2008). Species of ticks on camels and their monthly population dynamics in Arar city, KSA. Assuit Veterinary Medical Journal, 54: 117.

Aktas M, Altay K, Ozubek S and Dumanli N (2012). A survey of Ixodid ticks feeding on cattle and prevalence of tick-borne pathogens in the Black Sea region of Turkey. Veterinary Parasitology, 187: 567-571. DOI:https://doi.org/10.1016/j.vetpar.2012.01.035

Al-Ahsa municipality official website (2020). Last accessed on February 1, 2020. Available at: DOI: https://www.alhasa.gov.sa/SitePages/Home.aspx

Alanazi AD, Al-Mohammed HI, Alyousif MS, Said AE, Salim B, Abdel-Shafy S, and Shaapan RM (2019). Species diversity and seasonal distribution of hard ticks (Acari: Ixodidae) infesting mammalian hosts in various districts of Riyadh province. Saudi Arabian Journal for Medical Entomology, 56: 1027-1032. DOI:https://doi.org/10.1093/jme/tjz036

Alessandra T and Santo C (2012). Tick-borne diseases in sheep and goats: Clinical and diagnostic aspects. Small Ruminant Research, 106: S6-S11. DOI:https://doi.org/10.1016/j.smallrumres.2012.04.026

Al-Khalifa MS, Diab FM and Khalil GM (2007). Man-threatening viruses isolated from ticks in Saudi Arabia. Saudi Medical Journal, 28: 1864-1867.

Annual report (2010). The Saudi National Meteorological Institute. Available at: www.pme.gov.sa.

Available at: http://www.birdlife.org

Banaja AA and Roshdy MA (1978). Observations on ticks (Acarina-Ixodoidea) of Saudi Arabia. Bulletin of the Faculty of Science at King Abdulaziz University in Jeddah (Journal of King Abdulaziz University), 2: 119-122.

Barbieri ARM, Szabó MPJ, Costa FB, Martins TF, Soares HS, Pascoli G, Torga K, Saraiva DG, Ramos VN, Osava C et al. (2019). Species richness and seasonal dynamics of ticks with notes on rickettsial infection in a Natural Park of the Cerrado biome in Brazil. Ticks and Tick Borne Diseases, 10: 442-453. DOI:https://doi.org/10.1016/j.ttbdis.2018.12.010

Bartikova P, Holikova V, Kazimirova M and Štibraniova I (2017). Tick-borne viruses. Acta Virologica, 61: $413-427$. DOI:http://dx.doi.org/10.4149/av_2017_403

Bird Life International (2019). Accessed on December $18^{\text {th }}, 2019$.

Brossard M and Wikel SK (2004). Tick immunobiology. Parasitology, 129: S161-176. 
Chandler C and Read P (1994). Introduction to parasitology, Jhon Weakly and Sons Inc. UK, 10: 882.

Diab FM, Al-Khalifa MS, Al-Asgah NA, Hussein HS and Khalil GA (2006). Ticks (Acari: Argasidae, Ixodidae) infesting livestock in Saudi Arabia. Fauna Arabia, 22: 233-243.

Dohm DJ, Logan TM, Linthicum KJ, Rossi CA and Turell MJ (2014). Transmission of Crimean-Congo hemorrhagic fever virus by Hyalomma impeltatum (Acari: Ixodidae) after experimental infection. Journal of Medical Entomology, 33: 848-851.

El-Azazy OME and Scrimgeour EM (1997). Crimean-Congo haemorrhagic fever virus infection in the western province of Saudi Arabia. Transactions of the Royal Society of Tropical Medicine and Hygiene, 91: 275-278.

El-Azazy OME, El-Metenawy TM and Wassef HY (2001). Hyalomma impeltatum (Acari: Ixodidae) as a potential vector of malignant theileriosis in sheep in Saudi Arabia. Veterinary Parasitology, 99: 305-309.

Friedhoff KT (1997). Tick-borne diseases of sheep and goats caused by Babesia, Theileria or Anaplasma spp. Parassitologia, 39: 99-109.

Gothe R (1999). Zecken Toxikosen Hieronyms, Munich, p. 377.

Guglielmone AA, Robbins RG, Apanaskevich DA, Petney TN, Estrada-Peña A, Horak IG (Edts) (2014). The Hard Ticks of the World (Acari: Ixodida: Ixodidae). Springer. DOI:https://doi.org/10.1007/978-94-007-7497-1

Harrison A, Robb GN, Alagaili AN, Hastriter MW, Apanaskevich DA, Ueckermann EA and Bennett NC (2015). Ectoparasite fauna of rodents collected from two wildlife research centres in Saudi Arabia with discussion on the implications for disease transmission. Acta Tropica, 147: 1-5. DOI:http://dx.doi.org/10.1016/j.actatropica.2015.03.022

Hoogstraal H, Wassef HY and Buttiker W (1981). Ticks (Acarina) of Saudi Arabia fam. Argasidae Ixodidae. Fauna of Saudi Arabia, 3: 25-110.

Hornok S, Kováts D, Horváth G, Kontschán J and Farkas R (2020). Checklist of the hard tick (Acari: Ixodidae) fauna of Hungary with emphasis on host-associations and the emergence of Rhipicephalus sanguineus. Experimental and Applied Acarology, 80: 311-328. DOI:https://doi.org/10.1007/s10493-019-00461-6

Hussein HS, Al-Asgah NA, Al-Khalifa MS and Diab FM (1991). The blood parasites of indigenous livestock in Saudi Arabia. Arab Gulf Journal of Scientific Research, 9: 143-160.

Jongejan F and Uilenberg G (2004). The global importance of ticks. Parasitology, 129: S3-S14.

Karim S, Budachetri K, Mukherjee N, Williams J, Kausar A, Hassan MJ, Adamson S, Dowd SE, Apanskevich D, Arijo A et al. (2017). A study of ticks and tick-borne livestock pathogensin Pakistan. PLoS Neglected Tropical Diseases, 11(6): e0005681. DOI:https://doi.org/10.1371/journal.pntd.0005681

Kariuki MW, Hassanali A and Ng'ang'a MM (2018). Characterisation of cattle anal odour constituents associated with the repellency of Rhipicephalus appendiculatus. Experimental and Applied Acarology, 76: 221-227. DOI:https://doi.org/10.1007/s10493-018-0304-5

Klitgaard K, Højgaard J, Isbrand A, Madsen JJ, Thorup K and Bødker R (2019). Screening for multiple tick-borne pathogens in Ixodes ricinus ticks from birds in Denmark during spring and autumn migration seasons. Ticks and Tick Borne Diseases, 10: 546-552. DOI:https://doi.org/10.1016/j.ttbdis.2019.01.007

Lumaret JP, Errouissi F, Floate K, Rombke J and Wardhaugh K (2012). A review on the toxicity and non-target effects of macrocyclic lactones in terrestrial and aquatic environments. Current Pharmaceutical Biotechnology, 13: 10041060. DOI:http://dx.doi.org/10.2174/138920112800399257

Lydecker HW, Etheridge B, Price C, Banks PB and Hochuli DF (2019). Landscapes within landscapes: A parasite utilizes different ecological niches on the host landscapes of two host species. Acta Tropica, 193: 60-65. DOI:https://doi.org/10.1016/j.actatropica.2019.02.022

Mans BJ, Gothe R and Neitz AWH (2004). Biochemical perspectives on paralysis and other forms of toxicoses caused by ticks. Parasitology, 129: S95-S111. DOI:https://doi.org/10.1017/S0031182003004670

Randolph SE (1994). Population dynamics and density-dependent seasonal mortality indices of the tick Rhipicephalus appendiculatus in eastern and southern Africa. Medical and Veterinary Entomology, 8: 351368. DOI:https://doi.org/10.1111/j.1365-2915.1994.tb00099.x

Robson J, Robb JM, Hawa NJ and Al-Wahayyib T (1969). Ticks (Ixodoidea) of domesticated animals in Iraq. 7. Seasonal incidence on cattle, sheep and goats in the Tigris-Euphrates valley plain. Journal of Medical Entomology, 6: 127-130.

Tonbak S, Aktas M, Altay K, Azkur AK, Kalkan A, Bolat Y, Dumanli N and Ozdarendeli A (2006). crimean-congo hemorrhagic fever virus: genetic analysis and tick survey in Turkey. Journal of Clinical Microbiology, 44: 41204124. DOI:https://doi.org/10.1128/JCM.00644-06

Tonelli BA and Dearborn DC (2019). An individual-based model for the dispersal of Ixodes scapularis by ovenbirds and wood thrushes during fall migration. Ticks and Tick Borne Diseases, 10: 1096-1104. DOI:https://doi.org/10.1016/j.ttbdis.2019.05.012

Walker AR, Bouattour A, Camicas JL, Estrada-Pena A, Horak IG, Latif AA, Pegram RG and Preston PM (2003). Ticks of domesticated animals in Africa: a guide to identification of species. The University of Edinburgh. Bioscience Reports. Edinburgh Scotland. U.K 